\title{
O UNIVERSO FEMININO COMO CENTRO DE INTERESSE E DE ESTUDO EM TESES DE DOUTORADO: NOTAS PARA REFLEXÃO A PARTIR DE UMA PESQUISA BIBLIOGRÁFICA
}

\author{
João Guilherme Rodrigues MENDONÇA ${ }^{1}$ \\ Paulo Rennes Marçal RIBEIRO
}

\begin{abstract}
RESUMO: O presente artigo se propõe a analisar produções acadêmicas de doutorado, que se utilizaram da mídia escrita em revistas voltadas especificamente ao público feminino, defendidas entre 1999 e 2007. O objetivo da pesquisa foi verificar como pesquisadores que tratam do tema têm contribuído para a compreensão do modo que a mulher é retratada na mídia escrita. As teses de doutorado foram escritas por mulheres que falam sobre o sexo feminino a partir de revistas destinadas prioritariamente para esse público, exceção feita no estudo da Revista de Educação Physica, que não guarda especificamente essa característica. Os resultados encontrados nas diferentes produções retratam a mulher em sua condição de submissão feminina; de culto ao corpo; e sua sexualidade, construindo de modo relativamente explicito, um ideal de mulher; o comportamento feminino condizente a classe social e ao espaço urbano; ser mãe; ser esposa; sua forma de pensar; sua educação; seu lugar de consumidora; seu lugar no espaço público; sua atuação no mercado de trabalho; e estereótipos a ser seguido e consumido. É possível concluir que as características que fazem parte do universo feminino referem-se à higiene da mulher das classes média e alta urbana; construção do novo papel social da mulher mãe; a mulher como necessitada de ajuda; a mulher que precisa ver seu corpo grávido governado e regulado pelos especialistas; interferir na subjetivação de meninas e mulheres contemporâneas em sua forma de pensar, e em sua educação; conceberem as mulheres como excelente opção de mercado consumidor; reconhecerem a necessidade de modificar seus hábitos e atitudes; por fim de educar o corpo da mulher.
\end{abstract}

PALAVRAS-CHAVE: Gênero. Mídia. Sexualidade. Revistas Femininas.

\section{Introdução}

O presente artigo se propõe a analisar as produções acadêmicas de doutorado, que se utilizaram da mídia escrita em revistas voltadas especificamente ao público feminino. O objetivo foi o de verificar de que modo a mulher é retratada nessas publicações.

\footnotetext{
${ }^{1}$ Doutorando em Educação Escolar. UNESP - Universidade Estadual Paulista. Faculdade de Ciências e Letras Pós-Graduação em Educação Escolar - Núcleo de Estudos da Sexualidade. UNIR - Universidade Federal de Rondônia - Departamento de Educação física. - Porto Velho - RO - Brasil. 78900-000 jgrmendonca@bol.com.br

${ }^{2}$ UNESP - Universidade Estadual Paulista Faculdade de Ciências e Letras - Departamento de Psicologia da Educação - Programa de Pós-Graduação em Educação Escolar - Núcleo de Estudos da Sexualidade. Araraquara - SP - Brasil. 14800-901 - paulorennes@terra.com.br
} 
Ao longo da revisão dessas pesquisas strictu senso, verificamos algumas produções onde as revistas utilizadas pelos pesquisadores não se destinavam especificamente à mulher. Contudo, as análises dos recortes dessas revistas estavam relacionadas à mulher e à identidade feminina. Acolhemos estas produções no rol das outras pesquisas midiáticas que se destinavam ao público feminino.

Será possível verificar no final, o interesse e o destaque que é utilizar-se de revistas voltadas para o público feminino para pesquisas acadêmicas relativas ao interesse específico de compreender o universo feminino. Há um significativo número de pesquisas publicadas que podem demonstrar a atualidade e importância da temática, como o estudo de Moraes (1982), há quase trinta anos, e os mais recentes de Cavalcante e Morais (2003), Souza-Leite (2007) e Leão et al. (2007).

\section{Revisão das teses sobre mídia impressa destinada ao público feminino}

Dos estudos de doutorado com pesquisas referentes ao uso de revistas como objeto de interesse, se destacam três Teses em Educação, uma em Lingüística e outra em História das Ciências, todas escritas por doutorandas mulheres. A mais antiga é de 1999 e a mais recente de 2007. Os estudos se relacionam a revistas destinadas a mulheres, exceto a tese de Silvana Goellner (1999) que retrata sobre a imagem de mulher no primeiro periódico específico de Educação Física, a Revista Educação Physica entre 1932 a 1945, com o título Bela, maternal e feminina: imagem de mulher na Revista Educação Physica. A autora revela que as mulheres vão alcançando um espaço onde o movimento e a forma corporal parece ascender em exigências: "Imagens coletivas e individuais porque representativas de determinados valores sociais do tempo em que foram elaborados e porque marcadas pelo olhar e pela história articular de quem as registrou / elaborou e de quem a viu / vê ou leu / lê.” (GOELLNER, 1999, p.1). A autora observa que o conteúdo geral da revista procurou “[...] educar o corpo da mulher e de homens, cuja energia física é observada como potencializadora de um gesto eficiente capaz de produzir mais e com mais rapidez.” (GOELLNER, 1999, p.2). Um dos objetivos que permeia a revista é o de incentivar a prática esportiva feminina, que é incentivada a ser bela, mãe e feminina e a modificar seus hábitose atitudes. É preciso ser bela através de empenho individual, e com esforço, insistência e tenacidade é preciso movimentar o corpo feminino. Além do culto e a promoção de ideais de belez, a revista também exalta a maternidade como missão da mulher. Há duas variações ao longo de sua existência. Até o final dos anos 30, a revista reconhece e promove a mulher-mãe destinada à melhoria da raça 
através dos princípios da eugenia e a higiene. Já com a entrada do Brasil na II Guerra, incorpora em seus artigos os ideais oficiais de cuidados com a Pátria, e a mulher-mãe é substituída pela mulher-cívica pronta para a guerra. A revista reconhece que, sobretudo no corpo da mulher, há a esperança e a garantia de futuras gerações. A maternidade vigora como a principal missão da mulher, que tem, portanto, a dupla função de garantir a maternidade tanto por interesse individual quanto social, e um compromisso com a regeneração e aprimoramento da raça. Os vários artigos incentivavam a prática da atividade física guardando em seus propósitos ideais higiênicos e de prática da eugenia:

Esses artigos, além de incentivarem a prática de atividades físicas, para homens e mulheres, chamam atenção dos leitores/as para questões delicadas, como por exemplo, o controle da procriação, algumas medidas profiláticas para evitar as taras e doenças físicas existentes na sociedade, o exame prénupcial e a esterilização dos anormais (deficientes físicos e mentais). A mensagem é clara: são apenas os filhos saudáveis aqueles que fazem um povo forte e esses são os desejados. (GOELLNER, 1999, p.89).

A Revista Educação Physica faz apologia à beleza branca e loura, além de incentivar casamentos entre pessoas jovens e de classe média alta com essas características para fecundar e nutrir filhos sadios. É importante ser feminina: “[...] ser feminina é ser, também, saudável e bela para cumprir os desígnios de seu sexo: casamento e procriação.” (GOELLNER, 1999, p.119).

A última frase da tese é significativamente feminista e profunda, e não poderia deixar de ser aqui reproduzida: "Bela, maternal e feminina, imagens afirmativas que permitem compreender que o corpo da mulher ao mesmo tempo em que é seu não lhe pertence.” (GOELLNER, 1999, p.168).

A pesquisa seguinte é de Maria José Leotti (2007), intitulada A imagem da mulher ou a mulher da imagem: um estudo discursivo sobre o imaginário feminino na publicidade, é analisa peças publicitárias veiculadas na revista Marie Claire, no período de 2003 a 2006, totalizando 42 anúncios. A autora procurou compreender a construção do imaginário feminino em propagandas impressas em uma revista que têm como público alvo a mulher, cujos anunciadores consideram as mulheres excelente opção de mercado consumidor, possibilitando a divulgação de propagandas específicas a este público. A análise dos diferentes anúncios mostrou que o “[...] fator central na estratégia do discurso publicitário é conciliar a visão de mundo do produto anunciado à visão do mundo consumidor [...]” (LEOTTI, 2007, p.248), desvelando uma produção para mulheres da classe A e B que continha as seguintes imagens de mulher: a) moderna, audaciosa, corajosa, aberta ao novo, ao diferente; b) jovem 
adolescente insegura; c) mulher profissional de sucesso; d) mulher mãe, esposa, executiva encorpada numa única pessoa; e) mulher executiva e vaidosa; f) imagem de mulher preocupada com a aparência; g) mulher com compromisso religioso do casamento; h) imagem de mulher independente, decidida e casada; i) jovens consumistas; j) imagem de mulher que espera promessa de marido; l) vaidosa, elegante e equilibrada; m) mulher romântica e mulher sonhadora.

Leni Vieira Dornelles (2002) com a tese Meninas no papel se utiliza de periódicos direcionados para meninas brasileiras do final da década de 1990, período em que se multiplicou as publicações para o público infanto-juvenil feminino, que representa importante fatia de consumidores de revistas. Essa autora procurou com a pesquisa verificar o processo de subjetivação de meninas na produção de revistas infantis no Brasil. Encontrou como resultado que a posição subjetiva de sujeito juvenescido nas produções discursivas e não discursivas das revistas infantis brasileiras produz efeitos na subjetivação de meninas e mulheres contemporâneas e, conseqüentemente, na forma de pensar a sua educação. A autora revela que as revistas “[...] disciplinam da mesma forma que as normas de civilidade do século XVI, imitam a auto-vigilância, o controle, o autogoverno, prescrevendo determinados cuidados (práticos) de si, inclusive a produção de disciplina da sexualidade.” (DORNELLES, 2002, p.157).

Maria Simone Vione Schwengber (2006) com a tese Donos de si? A educação de corpos grávidos no contexto da Pais \& Filhos, verifica como o discurso das práticas corporais governa e regula os corpos grávidos; e de que modo esse discurso colabora e concorre com o processo de politização contemporânea dos corpos grávidos. A autora estabelece o período de 1968 a 2004 como referências de pesquisa, e encontra como resultado que as práticas corporais alternativas, esportivas e de fitness, na revista, se constituem como elementos importantes de um discurso de “cuidado de si”, sobretudo ao produzirem diferentes posições de sujeitos como mãe cuidadosa (aquela que cuida e se cuida, carinhosa, flexível, preparada, atlética, participativa, resistente forte e sensual). Schwengber considera que a revista compreende as mães como necessitadas de ajuda, e para suprir essa demanda precisarão seguir as determinações dos peritos/as em seus artigos nas revistas:

A Pais \& Filhos, partindo da premissa de que as mães necessitam de ajuda, sugere como primeira regra que as mães sigam as instruções dos/as peritos/as; só conhecer as experiências de outras mães não é suficiente. O conhecimento das avós, nas revistas, é paulatinamente desvalorizado (por expressões como do tempo da vovozinha). (SCHWENGBER, 2006, p.4142, grifo nosso). 
Maria Martha de Luna Freire (2006) com a tese Mulheres, mães e médicos: discurso maternalista em revistas femininas (Rio de Janeiro e São Paulo, décadas de 1920), atuou com as revistas femininas Vida Doméstica e Revista Feminina, e investigou o processo de difusão da ideologia da maternidade cientifica nestas duas revistas para mulheres. A tese gira em torno da compreensão da aliança entre médicos dedicados à higiene infantil e mulheres das classes médias e altas urbanas. Aborda também a legitimação de tais médicos como especialistas em Puericultura e na construção do novo papel social da mãe.

Em relação aos períodos estudados pelas teses, temos a seguinte cronologia:

a) Primeira metade do século XX:

Freire (2006) - Período pesquisado: 1920

Goellner (1999) - Período pesquisado: 1932 a 1945.

b) Segunda metade do século XX:

Schwengber (2006) - Período pesquisado: 1968 a 2004 (século XXI)

Dornelles (2002) - Período pesquisado: 1990.

c) Século XXI:

Leotti (2007) - Período pesquisado: 2003 a 2006

\section{Análise}

As teses de doutorado guardam pontos comuns e de contrastes em suas construções. Um primeiro aspecto interessante a ser ressaltado é que todas escritas por mulheres que falam sobre o sexo feminino a partir de revistas destinadas prioritariamente para esse público, exceção feita no estudo da Revista de Educação Physica, que não guarda especificamente essa característica. É possível apreender que as revistas escolhidas para estudo revelaram, de modo geral, tentativas mais ou menos explicitas de construir um ideal - um vir-a-ser como característica esperada para fazer parte do universo feminino. Estas característica nas teses estudadas referem-se à higiene das mulheres das classes médias e altas urbanas; construção do novo papel social da mulher mãe; a mulher como necessitada de ajuda; a mulher que precisa ver seu corpo grávido governado e regulado pelos especialistas; interferir na subjetivação de meninas e mulheres contemporâneas na sua forma de pensar e na sua educação; conceberam as mulheres como excelente opção de mercado consumidor, reconhecendo a necessidade de modificar seus hábitos e atitudes; e, por fim, educar o corpo da mulher.

Como é possível verificar, o corpo da mulher parece atrair a atenção, não só das revistas exploradas escolhidas para estudo no doutorado, mas também revelam o interesse 
próprio de cada uma das doutorandas. O que há nessa dimensão do feminino, revelada em sua diferença anatômica, que mobiliza esses atores - produtores das revistas e doutorandas?

Uma das especificidades focais é a maternidade, tema que Goellner (1999) verificou estar presente na ideologia das primeiras décadas do século XX, quando era exaltada como missão da mulher. A mulher-mãe revelada em sua pesquisa estava destinada à melhoria da raça. Já Schwengber (2006) apontou em seu trabalho a percepção de uma revista sobre o quanto as mães necessitam de ajuda, além de revelar que há uma dissociação entre o corpo da mulher e o corpo da mulher gestante, esta última posicionada como sujeito aprendente. Freire (2006) analisa a aliança entre médicos e as mulheres, os primeiros se dedicando à higiene das mulheres, atentos na edificação de um novo papel social de mãe, com base na higiene e a puericultura.

Outra especificidade focal é a adolescência, estudada por Dornelles (2002) em sua tese Meninas no papel. A autora constata que no final da década de 1990 inicia sistematização nas produções de periódicos destinados a esse público; e que estas disciplinam a auto-vigilância, o controle e o autogoverno, representando a constituição do modo de se pensar e de se portar. Na busca de compreender a subjetivação dessa produção de revistas infantis, constatou-se a produção de disciplina da sexualidade. Como em relação às outras revistas pesquisadas nas diferentes teses, a sexualidade do corpo feminino parece ser o foco do olhar de quem escreve e produz as revistas impressas.

Por último, temos a a tese de Leotti (2007), em que a atenção recai sobre a mulher consumidora, tendo como objeto de análise o imaginário feminino veiculado nas revistas a partir da publicidade dirigida a mulher por meio dos anúncios nelas impressos. Os publicitários e/ou os anunciantes acreditam em um perfil de mulher o qual precisa ser explorado para que sejam atingidas e estimuladas pelos produtos anunciados.

\section{Considerações finais: compreendendo as produções acadêmicas}

O universo feminino foi explorado nas pesquisas por vários caminhos e diferentes estratégias, tendo em comum o imaginário sobre a mulher presente no conteúdo das revistas. No entanto, aquilo que se imagina como perfil de mulher não é necessariamente o que as mulheres pensam sobre si mesmas, já que os responsáveis pelos textos destas publicações (autores, editores, publicitários) não são necessariamente mulheres, ainda que as revistas fôssem produzidas para o público feminino. 
Os resultados encontrados nas diferentes produções acabam retratando a condição de submissão feminina ao mesmo tempo em que o corpo é cultuado; construindo de modo mais ou menos explicito um ideal de mulher; valorizando a mulher mãe e esposa; determinando o lugar da mulher em vários contextos; criando ou reforçando esteriótipos.

Estudos utilizando revistas femininas são importantes não apenas para se conhecer o universo feminino a partir de um objeto que faz parte de forma ampla e abrangente da vida de homens e mulheres, mas principalmente porque analisam aquilo que, embora escondido, influencia o pensamento e ação de um significativo número de mulheres, determinando comportamentos e atitudes, sugerindo ou impondo valores, moldando um perfil que não necessariamente contribua para a vida social e psicológica das mulheres.

\title{
THE FEMININE UNIVERSE AS CENTER OF INTEREST AND STUDY FOR DOCTORATE THESIS: NOTES FOR REFLEXION FROM ONE BIBLIOGRAPHIC SEARCH
}

\begin{abstract}
This article purposes to analyze academic doctorate productions that used the written media in magazines that are dedicated exclusively for feminine public, defended between 1999 and 2007. The aim of research was verify how researchers that work with this theme have contributed for understanding of way that woman is portrayed in written media. The doctorate thesis was written for women that talk about the female sex from magazines that are principally made for this audience, exception for the study of Physical Education Review, that don't carry this character. The results found at different productions portray the woman in her condition of feminine submission; of cult to body; and her sexuality, building in a relatively explicit way, one pattern of woman; the matched feminine behavior with social class and urban space; be mother; be wife; her way of thinking; her education; her place as consumer; her place in the public space; her action in labor market; and stereotypes to follow and consume. It is possible to conclude that characters that be part of feminine universe report to hygiene of urban medium and high class woman; building of new social roll of mother woman; woman as a help needer human; a woman that needs to see her pregnant body ruled and regulated for experts; interpose in subjectivism of contemporary girls and women in their way of thinking and their education; conceive women as excellent option of consume market; recognize the need of modify their habits and attitudes; finally educate the woman's body.
\end{abstract}

KEYWORDS: Gender. Media. Sexuality. Feminine Magazines.

\section{REFERÊNCIAS}

CAVALCANTE, I. F.; MORAIS, M. A. C. de. Lendo o amor e a sexualidade na revista Realidade. In: CARVALHO. M. E. P. de ; PEREIRA, M. Z. da C. (Org.) Gênero e

educação: múltiplas faces. João Pessoa: Editora Universitária UFPB, 2003, p.235-243. 
DORNELLES, L. V. Meninas no papel. 2002. 175 f.Tese. (Doutorado em Educação) Faculdade de Educação, Universidade Federal do Rio Grande do Sul, Porto Alegre, 2002.

FREIRE, M. M. de L. Mulheres, mães e médicos: discurso maternalista em revistas feminina (Rio De Janeiro e São Paulo, décadas de 1920). 2006. 313 f. Tese (Doutorado em História das Ciências e da Saúde) - Casa de Oswaldo Cruz, Fundação Oswaldo Cruz, Rio de Janeiro, 2006.

GOELLNER, S. V. Bela, maternal e feminina: imagem de mulher na Revista Educação Phisica. 1999. 152 f. Tese (Doutorado em Educação) - Faculdade de Educação, Universidade Estadual de Campinas, Campinas, 1999.

LEÃO, A. M. C. et al. O machismo dissimulado pela sotisficação: estudo analítico-descritivo da Revista Playboy. Cadernos de formação cultural: experiências e teorias, Ribeirão Preto, n.4, p.75-94, 2007.

LEOTTI, M. J. A imagem da mulher ou a mulher da imagem: um estudo discursivo sobre o imaginário feminino na publicidade. 2007. 257 f. Tese (Doutorado em Línguistica) - Centro de Artes e Comunicação, Universidade Federal de Pernambuco, Recife, 2007.

MORAES, M. L. Q. de. A “nova” moral sexual das revistas femininas. In: MANTEGA, G. (Coord.). Sexo e poder. São Paulo: Círculo do Livro, 1982, p.61-75.

SCHWENGBER, M. S. V. Donas de si? a educação de corpos grávidos no contexto da Pais \& Filhos. 2006. 192 f. Tese. (Doutorado em Educação) - Faculdade de Educação, Universidade Federal Rio Grande do Sul, 2006.

SOUZA-LEITE, C. R. V. de. O zigue-zague da sexualidade da adolescente atrevida.

Cadernos de formação cultural: experiências e teorias, Ribeirão Preto, n.4, p.9-74, 2007. 